\title{
Applied Mathematical Theory for Monetary-Fiscal Interaction in a Supranational Monetary Union
}

\author{
Bodo Herzog \\ ESB Business School, Reutlingen University, Reutlingen, Germany \\ Email: Bodo.Herzog@Reutlingen-University.de
}

Received 18 April 2014; revised 20 May 2014; accepted 5 June 2014

Copyright (C) 2014 by author and Scientific Research Publishing Inc. This work is licensed under the Creative Commons Attribution International License (CC BY). http://creativecommons.org/licenses/by/4.0/ c) (i) Open Access

\begin{abstract}
I utilize a differentiable dynamical system á la Lotka-Voletrra and explain monetary and fiscal interaction in a supranational monetary union. The paper demonstrates an applied mathematical approach that provides useful insights about the interaction mechanisms in theoretical economics in general and a monetary union in particular. I find that a common central bank is necessary but not sufficient to tackle the new interaction problems in a supranational monetary union, such as the free-riding behaviour of fiscal policies. Moreover, I show that supranational institutions, rules or laws are essential to mitigate violations of decentralized fiscal policies.
\end{abstract}

\section{Keywords}

Differential Equations, Monetary-Fiscal Interaction, Monetary Union Theory

\section{Introduction}

This paper studies the theoretical implications of monetary and fiscal interaction in a monetary union. This is an urgent and interesting topic, especially since the European sovereign debt crisis in 2010. I utilize an approach from applied mathematics in order to model the economic interactions in a supranational monetary union. A differentiable dynamical system, similar to a Lotka-Volterra model, turns out to be well suited for studying this problem. Overall, my mathematical model is literally interdisciplinary and links two, up to now, hardly unconnected areas: the theory of differential equations and monetary economics.

It is not surprising that there are relatively few economic models that capture the sophisticated subspace of monetary-fiscal interaction. This has to do with the complexity and dynamics in this field of economics. So far, it is common practice in the economics literature to apply a game theoretic approach to study this question [1]- 
[4]. However, these models lack of dynamics and fail to incorporate the complexity of monetary-fiscal interaction. Consequently, a new applied mathematical model in theoretical economics needs to be both tractable and comprehensible for mathematical economists. I build such a model based on differential equations.

The remainder of the paper is structured as follows: Section 2 explains the model and discusses some propositions. I show the existence, stability and solution of the model as well as the economic implications in general. Finally, Section 3 concludes the paper.

\section{The Model}

\subsection{Economic Model}

The model's framework consists of three interacting institutions. The first institution is the European Central Bank (ECB) that is centralized in a monetary union. The primary objective of monetary policy is to maintain price-stability according to Article 105 in the Treaty on the Functioning of the European Union (TFEU). The ECB, however, interacts with the decentralized fiscal policies, the second institution in the model. Both institutions, in particular the central bank, determine the common interest rate. At the moment, there are 18 member countries and thus fiscal policies in the euro area. The main difference between monetary and fiscal policy is that the fiscal authorities retain full sovereignty at the national level. The third institution is supranational law or governance, such as the Stability and Growth Pact (SGP), the European Stability Mechanism (ESM) and other legal constraints [5]. The supranational rules and laws mainly limit the decentralized fiscal policies and support the goals of the centralized monetary policy. The major problem in a monetary union is known as fiscal policy free-riding and moral hazard [6]-[8]. Consequently, the model consists of three interaction channels:

a) Monetary policy interacts with fiscal policy. The decision about the level of public deficits and debts have an impact on the common central bank.

b) Fiscal policy in one member country interacts with the other fiscal policies in the monetary union. There is competition about the public good "price-stability" provided by ECB. One fiscal policy can undermine the supranational objective and transfer the cost to all countries; i.e. through free-riding.

c) Supranational law defines the level playing field for all institutions. These rules interact with both fiscal policies and the central bank. The main objective is the mitigation of fiscal heterogeneity as well as free-riding and moral hazard.

The paper analyzes these interaction channels in a monetary union in general. I utilize a mathematical model that consists of differential equations. Until now, economic literature has studied these interactions mainly in game theoretic models [2]. The first model in this field of literature was developed by Beetsma and Uhlig [5]. All economic models lack of a rigorous modeling of the full interactions and the simultaneous linkages. Moreover, the economic literature focuses on the level of nominal and real variables and it does not study the dynamic processes [9]. To my knowledge, there is no paper that utilizes a mathematical model based on differential equations to capture these interactions in a monetary union. Given the current policy challenges in Europe, my model offers important policy lessons.

\subsection{Applied Mathematical Model}

First of all, I model the interaction of fiscal policies and the supranational law respectively. Suppose, $x(t)$ is the number of fiscal policies with excessive national public deficit and debt levels. Hence, $x(t)$ measures the number of countries in violation of supranational law, i.e. the Stability and Growth Pact (SGP) which is a simple deficit and debt rule ${ }^{1}$. The dynamic yields

$$
x_{t}^{\prime}=(g-p \times s) x_{t} \quad t>0, \quad x(0)=x_{0} .
$$

The $g>0$ represents the benefits fiscal policies obtain through debt accumulation and free-riding. Deficit spending induces a short-run growth stimulus and thus higher domestic GDP. But the costs of higher deficits in one country, i.e. higher interest rates, have to be paid by all euro area member countries. The product $p \times s$ represents the punishment in case of violation with the supranational debt rule. According to the rule, the punishment is a fixed amount, $s$, of the GDP (cf. SGP). The parameter, $p>0$, represents the probability of detection of a fiscal policy failure. Hence, the first-order differential Equation (1) has an intuitive economic interpretation.

${ }^{1}$ The Stability and Growth (SGP) limits public deficits to 3\% of GDP and debt to $60 \%$ of GDP. 
The higher domestic benefits from deficit spending than punishment $(g-p s>0)$, the greater the number of fiscal policies violating the supranational debt rule. However, if countries do not consolidate the public budget according to the supranational rule, they have to pay a sanction if it is detected. Hence, the rule should mitigate the number of violating countries.

The solution of the model is $x(t)=x_{0} \mathrm{e}^{(g-p \times s) t}$. This solution reveals, again, as long as debt accumulation (free-riding incentive) is greater than the sanction $g-p s>0$, countries prefer free-riding. Only sufficiently high sanctions, $s$, or a high detection probability, $p$, mitigate the problem. Unfortunately, the enforcement of European law is rather weak and thus, $p$, is low in reality [10] [11]. Moreover, the sanction scheme, $s$, is rather limited today as well ${ }^{2}$. A more comprehensive modeling of the sanction scheme is

$$
s_{t}=s\left(x_{t}\right)=s_{0}+a \times x_{t} \quad s_{0}, a \geq 0 .
$$

The sanction payment $s_{t}$ depends on a fixed rate $s_{0}$ and variable rate $a$. The parameter $a$ depends on the number of breaching fiscal policies, $x_{t}$, and is economically a marginal propensity of sanctions. After substitution of Equation (2) in Equation (1), I obtain

$$
\frac{\mathrm{d} x(t)}{\mathrm{d} t}=x^{\prime}(t)=\left(\zeta_{1}^{F}-p \times a \times x_{t}\right) x_{t} \text { with } t>0, x(0)=x_{0},
$$

where $\zeta^{F}:=g-p \times s_{0}$ is a constant. The differential Equation (3) is a so-called logistic-differential equation or Verhulst-Model. I obtain the solution of that differential equation through integration

$$
\begin{aligned}
t & =\int_{0}^{t} \mathrm{~d} \tau=\int_{x(0)}^{x(t)} \frac{\mathrm{d} x}{\left(\zeta^{F}-p \times a \times x\right) x}=\int_{x_{0}}^{x(t)} \frac{1}{\zeta^{F}}\left(\frac{1}{x}+\frac{p a}{\zeta^{F}-p a \times x}\right) \mathrm{d} x \\
& =\frac{1}{\zeta^{F}}\left(\ln \left[\frac{x(t)}{x_{0}}\right]+p a \times \ln \left[\frac{\zeta^{F}-p a \times x_{0}}{\zeta^{F}-p a \times x(t)}\right]\right) .
\end{aligned}
$$

Finally, I solve the equation for $x(t)$,

$$
x(t)=\frac{\zeta^{F} \times x_{0}}{p a \times x_{0}+\left(\zeta^{F}-p a \times x_{0}\right) \mathrm{e}^{-\zeta^{F} t} .}
$$

This solution has the following boundaries for $t \rightarrow \infty$ :

$$
x(t) \rightarrow \begin{cases}\zeta^{F} /(p a) & \text { if } \zeta^{F}>0, \\ 0 & \text { if } \zeta^{F}<0 .\end{cases}
$$

If supranational law is fully effective, i.e. the detection probability $p$ and the fixed sanction $s_{0}$ are high, then the number of breaching countries converge to zero. However, if $\zeta^{F}>0$, i.e. $g-p \times s_{0}>0$, the number of breaching countries $x(t)$ convergence to $\zeta^{F} /(p a)$. Obviously, only fully effective supranational law minimizes the number of breaching countries. In other words, the smaller $\zeta^{F}$ and the larger $p a$, the smaller the number of countries violating the rules. The term $\zeta^{F} /(p a)$ could be interpreted as a natural intake capacity of breaching countries in a monetary union.

Next, I study monetary policy. The main instrument of a common central bank is the interest rate level $y(t)$. Importantly, in a monetary union the key interest rate is an average rate that should be appropriate for almost all member countries. But high domestic public deficits and debts indirectly affect (increase) the common interest rate. Thus, there exists a fiscal policy spill-over to monetary policy through the interest rate channel. For simplicity, let me first abstract from the spill-over mechanism. I model the interest rate dynamics $y(t)$, again, through a differential equation

$$
y_{t}^{\prime}=\left(\zeta^{M}-d^{-1} \times y_{t}\right) y_{t}, \quad t>0, \quad y(0)=y_{0},
$$

where $y_{t}^{\prime}$ is the first derivative and economically the rate of change. In addition, $d \geq 0$ measures the target commitment of the central bank, i.e. low inflation. The greater $d$, the higher the interest rates and the lower

${ }^{2}$ The sanction is a linear function of GDP with a minimum payment $s_{0}$ and a maximum of 0.25 percent of GDP according to EU-Regulation No. 1467/97. 
inflation. If $d \rightarrow \infty$ the common central bank fully commits to the primary objective of price stability ${ }^{3}$. Hence, in this case the parameter $\zeta^{M}$ is dominating Equation (7). In the following, I define $c:=d^{-1}$. Finally, $\zeta^{M}$ represents a fixed punishment of the common central bank for the free-riding incentives of fiscal policies in a monetary union. Obviously, as already explained, a comprehensive model considers the fiscal spill-over mechanism, too. Thus, $\zeta^{M}$ depends on the number of breaching fiscal policies, such as

$$
\zeta^{M}\left(x_{t}\right)=-\zeta_{1}^{M}+\zeta_{2}^{M} x_{t} \quad \text { with } \quad \zeta_{1}, \zeta_{2} \geq 0,
$$

where $\zeta_{1}^{M}$ represents the central bank reaction to publicly sound fiscal policies. This group of countries lower the common interest rate. And $\zeta_{2}^{M}$ depicts the effect of breaching (unsound) fiscal policies. These countries endanger inflation in the whole monetary union. Thus, the common central bank has to increase the common rate for all member countries. Consequently, the benefits of domestic deficit spending pass through a higher interest rate to all member countries. Furthermore, I generalize $\zeta^{F}$. The incentive of free-riding is dependent on the interest rate level $y_{t}$ :

$$
\zeta^{F}\left(y_{t}\right)=\zeta_{3}^{F}-\zeta_{4}^{F} y_{t} \quad \text { with } \zeta_{3}, \zeta_{4} \geq 0,
$$

where $\zeta_{3}^{F}$ represents the free-rider incentives in a monetary union [4] and $\zeta_{4}^{F}$ measures the disciplining effect of higher interest rates on the free-riding behaviour. In the next section, I study the complete fiscal-monetary interaction.

\subsection{General Mathematical Model}

Analyzing the complete dynamics of the fiscal-monetary-law interaction reveals new insights about the necessary and sufficient conditions for a long-run stable and sustainable monetary union. Using Equations (3) and (7) together with conditions (8) and (9), yields the following system:

$$
\begin{aligned}
& x_{t}^{\prime}=\left(\zeta_{3}^{F}-\zeta_{4}^{F} \times y_{t}-p a \times x_{t}\right) x_{t} \quad t>0 \quad x(0)=x_{0} \\
& y_{t}^{\prime}=\left(-\zeta_{1}^{M}+\zeta_{2}^{M} \times x_{t}-c \times y_{t}\right) y_{t} \quad t>0 \quad y(0)=y_{0}
\end{aligned}
$$

Interestingly, this system of two differential equations is similar to a so-called "Lotka-Volterra" model, developed by Alfred James Lotka (1880-1949) and Vito Volterra (1860-1949), and is an useful concept in applied mathematics [12]. To understand how the fiscal-monetary-law model evolves over the time, I first simplify the equations and assume $a=c=0$. This system has two possible solutions $\left(x_{1}, y_{1}\right)^{\prime}$ and $\left(x_{2}, y_{2}\right)^{\prime}$ :

$$
\left(\begin{array}{l}
x_{1} \\
y_{1}
\end{array}\right)=\left(\begin{array}{l}
0 \\
0
\end{array}\right) \text { and }\left(\begin{array}{l}
x_{2} \\
y_{2}
\end{array}\right)=\left(\begin{array}{c}
\zeta_{1}^{M} / \zeta_{2}^{M} \\
\zeta_{3}^{F} / \zeta_{4}^{F}
\end{array}\right) .
$$

The asymptotic stability or instability of the model can be studied. I define the function $F(x, y)$ and calculate the eigenvalues. The function is,

$$
F(x, y)=\left(\begin{array}{c}
\left(\zeta_{3}^{F}-\zeta_{4}^{F} y_{t}\right) x_{t} \\
\left(-\zeta_{1}^{M}+\zeta_{2}^{M} x_{t}\right) y_{t}
\end{array}\right) \quad x_{t}, y_{t} \geq 0 .
$$

The first derivative for the two solutions yields

$$
F^{\prime}(0,0)=\left(\begin{array}{cc}
\zeta_{3}^{F} & 0 \\
0 & -\zeta_{1}^{M}
\end{array}\right), \quad \wedge \quad F^{\prime}\left(\frac{\zeta_{1}^{M}}{\zeta_{2}^{M}}, \frac{\zeta_{3}^{F}}{\zeta_{4}^{F}}\right)=\left(\begin{array}{cc}
0 & -\zeta_{4}^{F} \frac{\zeta_{1}^{M}}{\zeta_{2}^{M}} \\
\zeta_{2}^{M} \frac{\zeta_{3}^{F}}{\zeta_{4}^{F}} & 0
\end{array}\right)
$$

Consequently, the eigenvalues of $F^{\prime}(0,0)$ are computed by $\operatorname{det}\left|F^{\prime}(0,0)-\lambda I\right|=\left(\zeta_{3}^{F}-\lambda_{1}\right)\left(-\zeta_{1}^{M}-\lambda_{2}\right)=0$. This implies $\lambda_{1}=\zeta_{3}^{F}$ and $\lambda_{2}=-\zeta_{1}^{M}$. From an economic point of view $\zeta_{i}>0 \quad \forall i$, and thus $\lambda_{1}>0$ and

${ }^{3}$ According to article 105 TFEU “... the primary objective of the... [European Central Bank]... is price stability.” The US-Federal Reserve Bank, however, has a dual mandate which means a lower $d$. 
$\lambda_{2}<0$. The system is instable, if $\operatorname{Re} \lambda_{1}<0$ and $\operatorname{Re} \lambda_{2}>0$. Hence, $P_{1}(0 ; 0)$ is an instable equilibrium. The instability can also be seen from $\operatorname{det}\left|F^{\prime}(0,0)\right|=-\zeta_{3}^{F} \zeta_{1}^{M}<0$. To determine the eigenvalue for $F^{\prime}\left(\frac{\zeta_{1}^{M}}{\zeta_{2}^{M}}, \frac{\zeta_{3}^{F}}{\zeta_{4}^{F}}\right)$, I solve the following problem

$$
\operatorname{det}\left|F^{\prime}\left(\frac{\zeta_{1}^{M}}{\zeta_{2}^{M}}, \frac{\zeta_{3}^{F}}{\zeta_{4}^{F}}\right)-\lambda I\right|=\lambda_{1} \times \lambda_{2}+\zeta_{2}^{M} \frac{\zeta_{3}^{F}}{\zeta_{4}^{F}} \times \zeta_{4}^{F} \frac{\zeta_{1}^{M}}{\zeta_{2}^{M}}=\lambda_{1} \times \lambda_{2}+\zeta_{3}^{F} \times \zeta_{1}^{M}=0 .
$$

The second solution of the model $P_{2}\left(\zeta_{1}^{M} / \zeta_{2}^{M} ; \zeta_{3}^{F} / \zeta_{4}^{F}\right)$ is instable again, due to $\operatorname{Re} \lambda_{1}<0$ and $\operatorname{Re} \lambda_{2}>0$ or vice versa. But if $\lambda_{1}=\lambda_{2}$, I obtain $\lambda=\sqrt{-\zeta_{3}^{F} \times \zeta_{1}^{M}}$. Hence, there is the possibility of complex eigenvalues. This implies no real solution. Finally, I describe the solution behaviour of the model near a point $\left(\zeta_{1}^{M} / \zeta_{2}^{M} ; \zeta_{3}^{F} / \zeta_{4}^{F}\right)$, if the eigenvalues are complex. First, I rewrite the system as

$$
\frac{\mathrm{d} x}{\mathrm{~d} y}=\frac{\frac{\mathrm{d} x}{\mathrm{~d} t}}{\frac{\mathrm{d} y}{\mathrm{~d} t}}=\frac{x_{t}^{\prime}}{y_{t}^{\prime}}=\frac{\left(\zeta_{3}^{F}-\zeta_{4}^{F} \times y_{t}\right) x_{t}}{\left(-\zeta_{1}^{M}+\zeta_{2}^{M} \times x_{t}\right) y_{t}}
$$

Next, I integrate and obtain,

$$
-\ln \left[x_{t}^{\zeta_{1}^{M}}\right]+\zeta_{2}^{M} \times x_{t}=\int \frac{-\zeta_{1}^{M}+\zeta_{2}^{M} \times x_{t}}{x_{t}} \mathrm{~d} x=\int \frac{\zeta_{3}^{F}-\zeta_{4}^{F} \times y_{t}}{y_{t}} \mathrm{~d} y=\ln \left[y_{t}^{\zeta_{3}^{F}}\right]-\zeta_{4}^{F} \times y_{t}-\alpha,
$$

where $\alpha \in R$ is an integration constant. Consequently, all solutions $(x(t), y(t))^{\prime}$ satisfy the implicit solution:

$$
\ln \left[x(t)^{\zeta_{1}^{M}}\right]+\ln \left[y(t)^{\zeta_{3}^{F}}\right]-\zeta_{2}^{M} x(t)-\zeta_{4}^{F} y(t)=\alpha \quad \forall t \geq 0 .
$$

The integration constant $\alpha$ can be calculated from the initial condition $\left(x_{0}, y_{0}\right)^{\prime}$ :

$\alpha=\ln \left[x(0)^{\zeta_{1}^{M}}\right]+\ln \left[y(0)^{\zeta_{3}^{F}}\right]-\zeta_{2}^{M} \times x(0)-\zeta_{4}^{F} \times y(0)$. I suggest that $(x(t), y(t))^{\prime}$ satisfy a closed-form solution in the environment $(\epsilon, \delta)$ around the point $\left(x_{2}, y_{2}\right)^{\prime}$,

$$
x_{2}(t)=\frac{\zeta_{1}^{M}}{\zeta_{2}^{M}}+\epsilon \sin [\omega t] \quad \text { and } \quad y_{2}(t)=\frac{\zeta_{3}^{F}}{\zeta_{4}^{F}}+\delta \cos [\omega t]
$$

where $\epsilon>0, \delta \ll 1$ and $\omega>0$. For $t=0$ and trivial aggregation it results:

$$
\alpha=\zeta_{1}^{M} \ln \left[\frac{\zeta_{1}^{M}}{\zeta_{2}^{M}}\right]+\zeta_{3}^{F} \ln \left[\frac{\zeta_{3}^{F}}{\zeta_{4}^{F}}\right]-\zeta_{1}^{M}-\zeta_{3}^{F}+|\mathcal{O}(\delta)| \quad(\delta \rightarrow 0) .
$$

The second-order Taylor approximation of the solution $(x(t), y(t))^{\prime}$ in the environment of $x_{2}=\zeta_{1}^{M} / \zeta_{2}^{M}$ and $y_{2}=\zeta_{3}^{F} / \zeta_{4}^{F}$ yields $\zeta_{1}^{M} \times \ln [x(t)]+\zeta_{3}^{F} \times \ln [y(t)]-\zeta_{2}^{M} \times x(t)-\zeta_{4}^{F} \times y(t)$, which is equivalent to:

$$
\begin{aligned}
& \zeta_{1}^{M} \ln \left[\frac{\zeta_{1}^{M}}{\zeta_{2}^{M}}\right]+\zeta_{2}^{M} \epsilon \sin \omega t+\zeta_{3}^{F} \ln \left[\frac{\zeta_{3}^{F}}{\zeta_{4}^{F}}\right]+\zeta_{4}^{F} \delta \cos \omega t+\frac{\zeta_{2}^{M 2}}{2 \zeta_{1}^{M}} \epsilon^{2} \sin ^{2} \omega t \\
& +\frac{\zeta_{4}^{F 2}}{2 \zeta_{3}^{F}} \delta^{2 M} \cos ^{2} \omega t-\zeta_{1}^{M}-\zeta_{2}^{M} \epsilon \sin \omega t-\zeta_{3}^{F}-\zeta_{4}^{F} \delta \cos \omega t+\mathcal{O}\left(\epsilon^{3}+\delta^{3}\right) \\
& =\zeta_{1}^{M} \ln \left[\frac{\zeta_{1}^{M}}{\zeta_{2}^{M}}\right]+\zeta_{3}^{F} \ln \left[\frac{\zeta_{3}^{F}}{\zeta_{4}^{F}}\right]-\zeta_{1}^{M}-\zeta_{3}^{F}+\frac{\zeta_{2}^{M 2}}{2 \zeta_{1}^{M}} \epsilon^{2} \sin ^{2} \omega t+\frac{\zeta_{4}^{F 2}}{2 \zeta_{3}^{F}} \delta^{2} \cos ^{2} \omega t+\mathcal{O}\left(\epsilon^{3}+\delta^{3}\right), \\
& =\alpha+\mathcal{O}\left(\epsilon^{2}\right) .
\end{aligned}
$$

This shows that that the specific solution solves the model for $(x(t), y(t))^{\prime}$ until an error term of order $\mathcal{O}\left(\epsilon^{2}\right)$. Moreover, the 'trajectories' $\{x(t), y(t): t \geq 0\}$ are approximative ellipses around the point $\left(x_{2}, y_{2}\right)^{\prime}$. The model reveals an interesting economic interpretation for $a=c=0$ : the model has an equilibrium with a 
certain number of fiscal policies breaching the supranational deficit and debt rule as long as the supranational law and central bank are ineffective and do not intervene in case of fiscal policy violations.

Finally, I study the full model of Equation (10) with $a \neq c \neq 0$. Again, I calculate the solutions and prove the stability of the associated equilibria. I obtain

$$
F\left(x_{t}, y_{t}\right)=\left(\begin{array}{c}
\left(\zeta_{3}^{F}-\zeta_{4}^{F} \times y_{t}-a p \times x_{t}\right) x_{t} \\
\left(-\zeta_{1}^{M}+\zeta_{2}^{M} \times x_{t}-c \times y_{t}\right) y_{t}
\end{array}\right) \quad x_{t}, y_{t} \geq 0 .
$$

The general model has four solutions:

$$
\left(\begin{array}{l}
x_{1} \\
y_{1}
\end{array}\right)=\left(\begin{array}{l}
0 \\
0
\end{array}\right) \wedge\left(\begin{array}{l}
x_{2} \\
y_{2}
\end{array}\right)=\left(\begin{array}{c}
0 \\
-\zeta_{1}^{M} / c
\end{array}\right) \wedge\left(\begin{array}{l}
x_{3} \\
y_{3}
\end{array}\right)=\left(\begin{array}{c}
\zeta_{3}^{F} /(a p) \\
0
\end{array}\right),
$$

and $\left(x_{4}, y_{4}\right)^{\prime}$ is the solution of the following linear system

$$
\left(\begin{array}{cc}
a p & \zeta_{4}^{F} \\
\zeta_{2}^{M} & -c
\end{array}\right)\left(\begin{array}{l}
x_{4} \\
y_{4}
\end{array}\right)=\left(\begin{array}{c}
\zeta_{3}^{F} \\
\zeta_{1}^{M}
\end{array}\right)
$$

Applying Cramer's rule, I obtain

$$
\left(\begin{array}{l}
x_{4} \\
y_{4}
\end{array}\right)=\frac{1}{a p c+\zeta_{2}^{M} \zeta_{4}^{F}}\left(\begin{array}{c}
\zeta_{3}^{F} \times c+\zeta_{4}^{F} \times \zeta_{1}^{M} \\
\zeta_{3}^{F} \times \zeta_{2}^{M}-a p \times \zeta_{1}^{M}
\end{array}\right) .
$$

For later computation purposes, I define $A:=\zeta_{3}^{F} \times c+\zeta_{4}^{F} \times \zeta_{1}^{M}$ and $B:=\zeta_{3}^{F} \times \zeta_{2}^{M}-a p \times \zeta_{1}^{M}$. The stability of the solutions are computed via the function $F(x, y)$. The derivative yields

$$
F^{\prime}\left(x_{t}, y_{t}\right)=\left(\begin{array}{cc}
\zeta_{3}^{F}-\zeta_{4}^{F}-2 \text { pax }_{t} & -\zeta_{4}^{F} x_{t} \\
\zeta_{2}^{M} y_{t} & -\zeta_{1}^{M}+\zeta_{2}^{M} x_{t}-2 c y_{t}
\end{array}\right) .
$$

The point $\left(x_{1}, y_{1}\right)^{\prime}=(0,0)^{\prime}$ is non-stationary, because $\operatorname{Re} \lambda>0$. The second solution $\left(x_{2}, y_{2}\right)^{\prime}$ is nonstationary because $x_{t}, y_{t} ¥ 0$. The point $\left(x_{3}, y_{3}\right)^{\prime}$ is unstable, if $\zeta_{1}^{M} / \zeta_{2}^{M}<\zeta_{3}^{F} /(a p)$ or asymptotically stable, if $\zeta_{1}^{M} / \zeta_{2}^{M}>\zeta_{3}^{F} /(a p)$. The point $\left(x_{4}, y_{4}\right)^{\prime}$ has positive values, i.e. $x_{t}, y_{t} \geq 0$, for $\zeta_{1}^{M} / \zeta_{2}^{M}<\zeta_{3}^{F} /(a p)$. The eigenvalues of Equation (20) for $P\left(x_{4} ; y_{4}\right)$ are:

$$
\lambda_{1,2}=-\frac{1}{2}(a A+c B) \pm \sqrt{\frac{1}{4}(a A+c B)^{2}-\left(\zeta_{2}^{M} \zeta_{2}^{M}+a c\right) A B},
$$

where $A, B>0$ and they are defined as above. As long as $\operatorname{Re} \lambda_{1,2}<0$, the point $P\left(x_{4} ; y_{4}\right)$ is asymptotically stable. That means $(x(t), y(t))^{\prime} \rightarrow\left(x_{4}, y_{4}\right)^{\prime}$ for $t \rightarrow \infty$. Economically, it implies a certain number of fiscal policies violating the supranational deficit and debt rule. The following expressions summarize the results, for $t \rightarrow \infty$ :

$$
\begin{aligned}
& \frac{\zeta_{1}^{M}}{\zeta_{2}^{M}}>\frac{\zeta_{3}^{F}}{a p}: \quad x(t) \rightarrow \frac{\zeta_{3}^{F}}{a p} \text { and } y(t) \rightarrow 0 \\
& \frac{\zeta_{1}^{M}}{\zeta_{2}^{M}}<\frac{\zeta_{3}^{F}}{a p}: \quad x(t) \rightarrow \frac{\zeta_{3}^{F} c+\zeta_{4}^{F} \zeta_{1}^{M}}{a p c+\zeta_{2}^{M} \zeta_{4}^{F}} \text { and } y(t) \rightarrow \frac{\zeta_{3}^{F} \zeta_{2}^{M}-a p \zeta_{1}^{M}}{a p c+\zeta_{2}^{M} \zeta_{4}^{F}} .
\end{aligned}
$$

The first constellation becomes a reality if free-rider incentives are small $\left(\zeta_{3}^{F} \rightarrow 0\right)$ and the number of disciplined fiscal policies are great $\left(\zeta_{1}^{M} \rightarrow \infty\right)$. The next proposition reveals an answer to the following question: Is a supranational central bank sufficient to constrain the number of fiscal policies violating the supranational debt rule in a monetary union?

Proposition 1 The number of fiscal policies $x(t)$ in violation with a debt rule is always positive in a monetary union, as long as $\zeta_{3}^{F}, p$, and a are non-zero.

The proof of this proposition follows from Equation (21). First, the constellation $\zeta_{1}^{M} / \zeta_{2}^{M}>\zeta_{3}^{F} /(a p)$ is economically not realistic because the common interest rate converges for $t$ to infinity, to zero $(y(t) \rightarrow 0)$. Any- 
way, even in this case the number of breaching fiscal policies converge to a positive fixed ratio. For the second constellation $x(t)$ and $y(t)$ is always positive, too. This is surprising because it demonstrates that the common cental bank is ineffective in mitigating the free-riding incentives through higher interest rates. Consequently, effective supranational governance, that prevents debt accumulation of fiscal policies, is essential in a monetary union. Proposition 1 reveals that supranational governance is only effective if both the detection probability $p$ and the marginal sanction fee $a$ is high. In this case $x(t)$ and $y(t)$ declines because the free-riding incentives are less attractive. Unfortunately, the existing European fiscal and economic governance scheme is neither effective nor rigorously enforced. Consequently, the current sanction procedure in the European Monetary Union (EMU) has a low detection probability and a weak enforcement. Moreover, there are too many exceptions as well as loopholes, and the whole governance is under flawed partisan influence. Overall, this explains the importance of sustainable public finances and an efficient fiscal and economic governance scheme in a monetary union. Otherwise, a monetary union is doomed to fail. The final proposition discusses the sensitivity of the general model.

Proposition 2 For $p a \zeta_{1}^{M}<\zeta_{2}^{M} \zeta_{3}^{F}$, the number of fiscal policies $x(t)$ violating supranational law and the common interest rate $y(t)$, except for (iii), is low, if

a) the detection probability, $p$, is high;

b) the marginal sanction fee, $a$, is high;

c) central bank commitment, $d$, is high (i.e. $c$ is low).

Proof: The proof follows by direct differentiation of $x(t)$ and $y(t)$ :

$$
\begin{aligned}
& \frac{\partial x(t)}{\partial p}=-\frac{\left(\zeta_{3}^{F} c+\zeta_{4}^{F} \zeta_{1}^{M}\right)}{\left(a p c+\zeta_{2}^{M} \zeta_{4}^{F}\right)^{2}}<0 \\
& \frac{\partial y(t)}{\partial p}=\frac{-a \zeta_{1}^{M}\left(a p c+\zeta_{2}^{M} \zeta_{4}^{F}\right)-\left(\zeta_{3}^{F} \zeta_{2}^{M}-a p \zeta_{1}^{M}\right) p c}{\left(a p c+\zeta_{2}^{M} \zeta_{4}^{F}\right)^{2}}<0 .
\end{aligned}
$$

Part (ii), follows by differentiation in respect to $a$,

$$
\begin{aligned}
& \frac{\partial x(t)}{\partial a}=-\frac{p c\left(\zeta_{3}^{F} c+\zeta_{4}^{F} \zeta_{1}^{M}\right)}{\left(a p c+\zeta_{2}^{M} \zeta_{4}^{F}\right)^{2}}<0 \\
& \frac{\partial y(t)}{\partial a}=\frac{-p \zeta_{1}^{M}\left(a p c+\zeta_{2}^{M} \zeta_{4}^{F}\right)-\left(\zeta_{3}^{F} \zeta_{2}^{M}-a p \zeta_{1}^{M}\right) p c}{\left(a p c+\zeta_{2}^{M} \zeta_{4}^{F}\right)^{2}}<0 .
\end{aligned}
$$

Part (iii) is shown by

$$
\frac{\partial x(t)}{\partial c}=\frac{\zeta_{4}^{F}\left(\zeta_{3}^{F} \zeta_{2}^{M}-a p \zeta_{1}^{M}\right)}{\left(a p c+\zeta_{2}^{M} \zeta_{4}^{F}\right)^{2}}>0 \quad \frac{\partial y(t)}{\partial c}=-\frac{p a\left(\zeta_{3}^{F} \zeta_{2}^{M}-a p \zeta_{1}^{M}\right)}{\left(a p c+\zeta_{2}^{M} \zeta_{4}^{F}\right)^{2}}<0
$$

\section{Conclusion}

This paper explains the unique fiscal-monetary-law interaction in a supranational monetary union. I conclude the paper by discussing some generalizations and by touching on some issues that the model did not address. First, the argument is much more general than initially considered. The results reveal new insights about the interaction of the key institutions in a monetary union. The model demonstrates that without effective laws and fiscal and economic governance, a monetary union is doomed to fail. Consequently, the fiscal and economic governance scheme, together with the common cental bank, plays an important role in a monetary union. Second, the model is well designed to analyze the institutional drawbacks and interaction relationships in the EMU. The result suggests a tough sanction scheme for unsound fiscal policies. Only this can mitigate the potential benefits of free-riding. The major omission of the model is an endogenous economic-political element that considers for instance strategic policy decisions or veto power. Furthermore, an empirical investigation of the proposition is also an important study object in future research. Moreover, I do not consider the fact that small and weak agents ty- 
pically pay more attention to supranational law than powerful agents do.

\section{Acknowledgements}

I would like to thank for comments Mr. Gassmann and the two anonymous referees. I gratefully acknowledge financial support from the RRI-Reutlingen Research Institute.

\section{References}

[1] Libich, J. and Stehlik, P. (2012) Monetary Policy Facing Fiscal Indiscipline under Generalized Timing of Actions. Journal of Institutional and Theoretical Economics, 168, 393-431. http://dx.doi.org/10.1628/093245612802920962

[2] Dixit, A. and Lambertini, L. (2003) Interactions of Commitment and Discretion in Monetary and Fiscal Policies. The American Economic Review, 93, 1522-1542. http://dx.doi.org/10.1257/000282803322655428

[3] Beetsma, R. and Jensen, H. (2003) Contingent Deficit Sanctions and Moral Hazard with a Stability Pact. Journal of International Economics, 61, 187-208. http://dx.doi.org/10.1016/S0022-1996(02)00083-1

[4] Beetsma, R. and Bovenberg, L. (1999) Does Monetary Unification Lead to Excessive Debt Accumulation? Journal of Political Economics, 74, 299-325.

[5] Beetsma, R. and Uhlig, H. (1999) An Analysis of the Stability and Growth Pact. The Economic Journal, 109, 546-571. http://dx.doi.org/10.1111/1468-0297.00462

[6] Beetsma, R. and Bovenberg, L. (2001) The Optimality of a Monetary Union without Fiscal Union. Journal of Money, Credit, and Banking, 33, 179-204. http://dx.doi.org/10.2307/2673880

[7] Beetsma, R. and Bovenberg, L. (2002) Strategic Debt Accumulation in a Heterogeneous Monetary Union. Journal of Political Economics, 19, 1-15. http://dx.doi.org/10.1016/S0176-2680(02)00126-X

[8] Gali, J. and Monacelli, T. (2008) Optimal Monetary and Fiscal Policy in a Currency Union. Journal of International Economics, 76, 116-132. http://dx.doi.org/10.1016/j.jinteco.2008.02.007

[9] Kirsanova, T. and Wren-Lewis, S. (2012) Optimal Fiscal Feedback on Debt in an Economy with Nominal Rigidities. Economic Journal, 122, 238-264. http://dx.doi.org/10.1111/j.1468-0297.2011.02458.x

[10] Hallet, A.H. and Svend, H.J. (2012) Fiscal Governance in the Euro Area. Journal of European Public Policy, 19, 646664. http://dx.doi.org/10.1080/13501763.2011.646773

[11] Herzog, B. and Hengstermann, K. (2013) Restoring Credible Economic Governance to the Eurozone. Economic Affairs, 33, 2-17. http://dx.doi.org/10.1111/ecaf.12009

[12] Torbati, A.S. and Chakoli, A.N. (2013) Empirical Examination of Lotka’s Law for Applied Mathematics. Life Science Journal, 10, 601-607. 
Scientific Research Publishing (SCIRP) is one of the largest Open Access journal publishers. It is currently publishing more than 200 open access, online, peer-reviewed journals covering a wide range of academic disciplines. SCIRP serves the worldwide academic communities and contributes to the progress and application of science with its publication.

Other selected journals from SCIRP are listed as below. Submit your manuscript to us via either submit@scirp.org or Online Submission Portal.
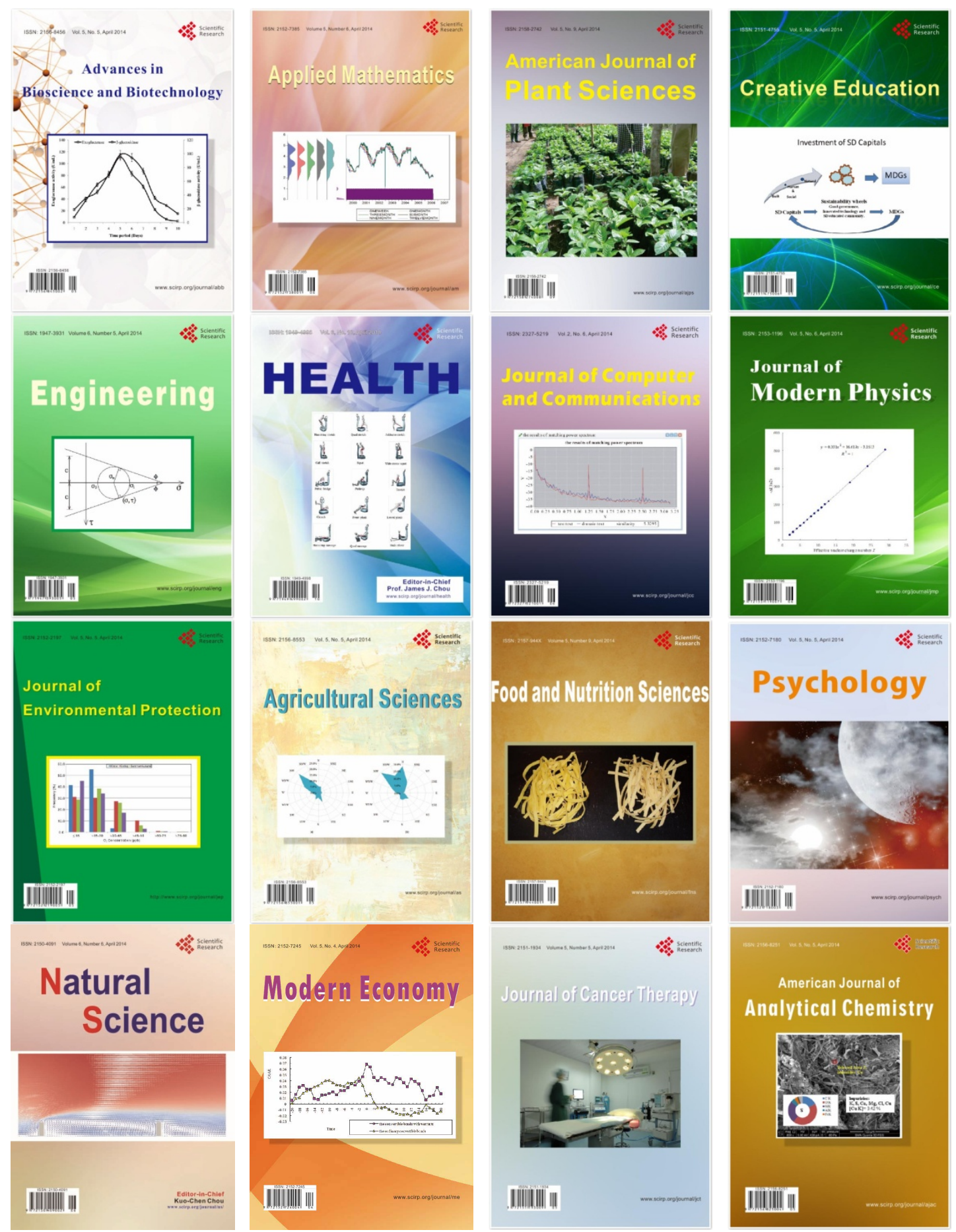